\title{
Advancing adolescent health and health services in Saudi Arabia: exploring health-care providers' training, interest, and perceptions of the health- care needs of young people
}

\author{
This article was published in the following Dove Press journal: \\ Advances in Medical Education and Practice \\ 4 September 2014 \\ Number of times this article has been viewed
}

\author{
Fadia S AlBuhairan ${ }^{1-3}$ \\ Tina M Olsson ${ }^{3,4}$ \\ 'Department of Pediatrics, King \\ Abdulaziz Medical City, Riyadh, \\ Saudi Arabia; ${ }^{2}$ King Saud bin \\ Abdulaziz University for Health \\ Sciences, Riyadh, Saudi Arabia; \\ ${ }^{3}$ King Abdullah International \\ Medical Research Center, \\ Riyadh, Saudi Arabia; ${ }^{4}$ School of \\ Social Work, Lund University, \\ Lund, Sweden
}

\begin{abstract}
Background: Adolescent health is regarded as central to global health goals. Investments made in adolescent health and health services protect the improvements witnessed in child health. Though Saudi Arabia has a large adolescent population, adolescent health-care only began to emerge in recent years, yet widespread uptake has been very limited. Health-care providers are key in addressing and providing the necessary health-care services for adolescents, and so this study was conducted with the aim of identifying opportunities for the advancement of knowledge transfer for adolescent health services in Saudi Arabia.
\end{abstract}

Methods: This Web-based, cross-sectional study was carried out at four hospitals in Saudi Arabia. Physicians and nurses were invited to participate in an online survey addressing their contact with adolescent patients, and training, knowledge, and attitudes towards adolescent health-care.

Results: A total of 232 professionals participated. The majority (82.3\%) reported sometimes or always coming into contact with adolescent patients. Less than half (44\%), however, had received any sort of training on adolescent health during their undergraduate or postgraduate education, and only $53.9 \%$ reported having adequate knowledge about the health-care needs of adolescents. Nurses perceived themselves as having more knowledge in the health-care needs of adolescents and reported feeling more comfortable in communicating with adolescents as compared with physicians. The majority of participants were interested in gaining further skills and knowledge in adolescent health-care and agreed or strongly agreed that adolescents have specific health-care needs that are different than children or adults $(82.3 \%$ and $84.0 \%$, respectively). With respect to health services, the majority ( $85.8 \%)$ believed that adolescents should be hospitalized in adolescent-specific wards. Only $26.7 \%$ of health-care providers believed that patients should be transferred from child to adult health-care services at 12-13 years of age, as is currently practiced in the country.

Conclusion: A gap exists between the training, knowledge and skills of health-care providers, and the needs to address health-care issues of adolescents in Saudi Arabia. This coupled with the fact that health-care providers are interested in gaining more knowledge and skills and are supportive of changes in the health-care system provides an opportunity for building local capacity and instituting medical and nursing education and health-care reform that can better serve the needs of the country's young population.

Keywords: medical education, young population, knowledge transfer

\section{Introduction}

The World Health Organization (WHO) defines adolescents as young people aged 10-19 years. ${ }^{1}$ This phase of life, the transition from childhood to adulthood, 
is characterized by major physical, psychological, cognitive, and behavioral developments. ${ }^{2}$ Due to this, health profiles and health status change rapidly during this period. ${ }^{3}$ Increasingly, adolescence is regarded as central to global health goals. This is due to four main features of adolescent health. First, compared with childhood, there is a striking increase in mortality and morbidity during adolescence. ${ }^{3-5}$ Second, a majority of premature adult deaths and health-risk behaviors that lead to chronic non-communicable diseases in later life typically originate during adolescence. ${ }^{3,5,6-12}$ Third, many of the health risks originating during adolescence and continuing into adulthood are preventable. ${ }^{13-15}$ Fourth, some of the health risks present during adolescence have intergenerational consequences. ${ }^{14}$ Thus, a focus on alleviating these health risks has far reaching impact for future population health.

The adolescent population is a key target for primary prevention activities, which creates special health-care needs for the population. The health-care provider has an important role to play in not only treating health problems but also promoting healthful behaviors and preventing disease. Research has identified relevant risks for the healthy development of adolescents as well as efficacious interventions which target structural, intermediate, and individual risk. ${ }^{13}$ However, the conditions under which adolescents seek health-care and disclose information are special for this group of patients. ${ }^{1}$ For example, the extent to which health-care visits are confidential and private ${ }^{16-18}$ and the extent to which health-care providers foster trust ${ }^{17}$ are important aspects of the visit. In addition, health-care providers frequently rely on adolescents or their parents to initiate discussion of health concerns, ${ }^{19}$ while studies show that adolescents tend not to disclose their health-risk behaviors unless prompted by health-care providers. ${ }^{20}$ There is evidence that adolescents regard adult or pediatric services, with no adjustments for their special needs, as irrelevant to their needs and thus distrust them. ${ }^{1}$ For the system that intends to improve individual and population health, a health-care workforce that is aware and knowledgeable of the important role adolescent health plays in the attainment of that goal and is sensitive to the needs of adolescents in seeking, engaging, and following through on health-care recommendations and engaging in healthy behaviors is necessary for the ultimate transfer of knowledge regarding efficacious and effective adolescent health services to health-care practice.

Adolescent health contributes to adult health and can deliver economic dividends to nations that invest wisely in adolescent health. ${ }^{21,22}$ In addition, the availability of adequate adolescent health services can protect the health investments made previously in infant and child health (eg, improvements in infant death rates and childhood diseases). Despite the conceivable population health benefits of investments in adolescent health-care, the health needs of adolescents have largely been overlooked. ${ }^{23}$ This is, at least in part, due to the fact that compared with adult populations, adolescent populations are considered "healthy" by health-care providers and policymakers.

Furthermore, although adolescent medicine has been a topic of concern for the past 60 years, training of physicians in adolescent medicine is largely confined to North America, where examination for subspecialty board certification has been possible for almost 20 years. ${ }^{23}$

\section{Adolescents and adolescent health-care in Saudi Arabia}

Adolescents comprise $20 \%$ of the population of the Kingdom of Saudi Arabia (KSA). ${ }^{24}$ The first clinic dedicated to the treatment of adolescents (aged 12-19 years) in KSA was formed in 1993 and focused on the treatment of endocrinological complaints. ${ }^{25}$ In 2007, the Saudi Commission for Health Specialties, the scientific commission that ensures healthcare providers' qualifications, provides accreditation and medical licenses, and is responsible for many other tasks, ${ }^{26}$ recognized adolescent medicine as a pediatric subspecialty. Subsequently, in 2008, the first specialty adolescent medicine clinic in the region was established within the Department of Pediatrics at King Abdulaziz Medical City in Riyadh and provides adolescents, aged 11-21 years, with secondary and tertiary care for a wide range of complex health conditions. The affiliated university incorporated adolescent health into its medical school curriculum, and postgraduate pediatrics residents have also been offered clinical and research training in adolescent health. Despite these initiatives, widespread uptake of adolescent health-care services and increases in physician education and training in KSA in adolescent health has not been realized.

Given the far-reaching potential health benefits of advances in adolescent health-care and the important role health-care providers play in the delivery of effective adolescent health-care services, this study was carried out with the overall aim of identifying opportunities for the advancement of knowledge transfer for the improvement of adolescent health services in Saudi Arabia. The purpose of this study is to 1) assess the extent to which health-care providers have contact with adolescents, 2) assess the extent to which health-care providers are trained and/or are knowledgeable in adolescent health issues, 3) assess the 
extent to which health-care professionals are interested in and comfortable with providing health-care services to adolescents, and 4) assess health-care professionals' perceptions of the health-care needs of adolescents.

\section{Method}

\section{Setting}

This study was conducted at the National Guard Health Affairs (NGHA) affiliated hospitals in Saudi Arabia. NGHA hospitals are academic hospitals that provide secondary and tertiary care to National Guard employees and their dependants. These hospitals also serve as referral centers for patients requiring advanced and specialized health-care. Patients at the NGHA hospitals are transferred from pediatric to adult care at 14 years of age. The adolescent medicine clinic within the department of pediatrics at the Riyadh-based hospital is an exception to this policy. Patients seen in this clinic are transferred to adult care at 21 years of age.

Adolescents older than 14 years of age and requiring hospital admission are admitted to an adult ward, where they may co-share a room with an elderly patient; similarly, a younger adolescent may be admitted to a pediatrics ward, where co-sharing of the room may take place with a younger child or infant. This practice is seen throughout hospitals in Saudi Arabia due to policy concerning age of transfer of patient from child to adult health-care services.

\section{Participants}

Physicians, including in-training physicians, and nurses $(\mathrm{N}=601)$ involved in direct patient care at four NGHA hospitals across KSA (Riyadh, Jeddah, Dammam, and Al Ahsaa) were invited to participate in the study.

\section{Data collection}

Eligible participants were sent an email invitation along with background information on the study in the spring of 2009. The invitation contained a hyperlink to an online survey instrument that was developed for the purpose of this study (instrument available upon request). Two subsequent email reminders were sent to participants at 2-week intervals.

\section{Statistical analysis}

The Pearson chi-square test for independence was used for all nominal data comparisons. With ordinal independent variables, the Mantel-Haenszel linear-by-linear chi-square association was tested. SPSS (IBM Corporation, Armonk, NY, USA) version 20.0.0.1 was used for analysis.
This study was approved by the King Abdullah International Medical Research Center prior to it being carried out.

\section{Results}

The final sample consisted of 232 respondents $(38.6 \%$ response rate). The demographic characteristics of respondents can be found in Table 1 .

\section{Health-care providers' training and specialties}

Physician respondents were educated in KSA (60.1\%), Pakistan (8.5\%), Syria (7.2\%), Egypt (5.2\%), India, Sudan, and the United Kingdom (3.3\% each), and other countries (all $<2 \%$ ). Of physician respondents, $85 \%$ were independently practicing, and $15 \%$ were physicians intraining (residents or fellows). Physicians had received some

Table I Demographic characteristics of study respondents (\%)

\begin{tabular}{|c|c|c|c|}
\hline Characteristic & $\begin{array}{l}\text { Physicians } \\
n=153\end{array}$ & $\begin{array}{l}\text { Nurses } \\
\mathrm{n}=79\end{array}$ & $\begin{array}{l}\text { Study } \\
\mathrm{n}=232 \\
\end{array}$ \\
\hline \multicolumn{4}{|l|}{ Age } \\
\hline$<24$ & 0.7 & 2.5 & 1.3 \\
\hline $25-29$ & 11.1 & $1 \mathrm{I} .4$ & 11.2 \\
\hline $30-34$ & 22.9 & 15.2 & 20.3 \\
\hline $35-39$ & 22.9 & 19.0 & 21.6 \\
\hline $40-44$ & 24.2 & 12.7 & 20.3 \\
\hline $45-49$ & 9.2 & 15.2 & 11.2 \\
\hline $50-54$ & 5.2 & 17.7 & 9.5 \\
\hline $55-59$ & 3.3 & 6.3 & 4.3 \\
\hline $60-64$ & 0.7 & 0 & 0.4 \\
\hline \multicolumn{4}{|l|}{ Sex } \\
\hline Male & 32.7 & 92.4 & 53 \\
\hline Female & 67.3 & 7.6 & 47 \\
\hline \multicolumn{4}{|l|}{ Country of origin } \\
\hline Saudi Arabia & 60.8 & 5.1 & 41.8 \\
\hline Philippines & 0 & 34.2 & 11.6 \\
\hline Pakistan & 7.2 & 1.3 & 5.2 \\
\hline South Africa & 0 & 15.2 & 5.2 \\
\hline Egypt & 5.2 & 2.5 & 4.3 \\
\hline United Kingdom & 2.6 & 7.6 & 4.3 \\
\hline Syria & 5.9 & 0 & 3.9 \\
\hline Jordan & 2.6 & 6.3 & 3.9 \\
\hline India & 2.6 & 3.8 & 3.0 \\
\hline Sudan & 4.6 & 0 & 3.0 \\
\hline Yemen & 3.9 & 0 & 2.6 \\
\hline Malaysia & 0 & 7.6 & 2.6 \\
\hline Australia & 0 & 5.1 & 1.7 \\
\hline \multicolumn{4}{|l|}{ NGHA region } \\
\hline Central & 58.2 & 45.6 & 53.9 \\
\hline Eastern & 22.9 & 12.7 & 19.4 \\
\hline Western & 19.0 & 41.8 & 26.7 \\
\hline
\end{tabular}

Note: Countries not listed all $<2 \%$.

Abbreviation: NGHA, National Guard Health Affairs. 
residency (19.6\%) or fellowship (35.3\%) training in North America or Europe. Physician specialty areas included pediatrics (26.7\%), internal medicine (10.3\%), emergency medicine $(7.8 \%)$, obstetrics/gynecology $(7.3 \%)$, family medicine $(6.9 \%)$, surgery $(4.7 \%)$, psychiatry $(1.3 \%)$, and neurology $(0.9 \%)$. Less than $1 \%$ of physicians $(n=2)$ responded that they had received subspecialty training in adolescent health.

Nurse respondents were educated in the Philippines (34.2\%), South Africa (15.2\%), Malaysia and United Kingdom (7.6\% each), Jordan (6.3\%), Australia and Saudi Arabia (5.1\% each), India (3.8\%), Egypt (2.5\%), and other countries (all $<2 \%$ ) (Table 1 ).

Of nurse respondents, $36.7 \%$ had received post-graduate education. Nurses worked primarily in pediatrics $(25.3 \%)$, oncology (24.1\%), emergency medicine (10.1\%), obstetrics/ gynecology $(5.1 \%)$, and cardiology and family medicine (2.5\% each).

\section{Contact with adolescents}

The majority of respondents $(82.3 \%)$ reported that they had contact with adolescent patients sometimes or always, whereas, $17.7 \%$ reported never or rarely having contact. Nurses $(58.2 \%)$ reported more regular contact with patients between the ages of 12 and 18 years than physicians $(27.5 \%)$ $(P \leq 0.001)$. Pediatric physicians $(16.1 \%)$ reported having significantly less contact with patients between the ages of 12 and 18 years than physicians in other departments $(45.9 \%)$ $(P \leq 0.001)$. Contact with patients aged $12-18$ years was not found to be dependent on nursing specialty $(P=0.52)$.

\section{Specific training in adolescent health}

Of the respondents, $44 \%$ reported that they were specifically trained to provide health-care services to adolescents during their training. Nurses $(53.2 \%)$ were more likely to report having had training in adolescent health than physicians
$(39.2 \%)(P \leq 0.05)$. Having had specific training in adolescent health was independent of physician specialty $(P=0.70)$ and nursing department $(P=0.18)$.

\section{Health-care providers' understanding of adolescence and their self-reported knowledge of adolescents' health- care needs}

Fifteen percent of respondents correctly identified the age of adolescence (10-19 years) as defined by the WHO. Ability to identify the age of adolescence as defined by the WHO was independent of profession $(P=0.25)$ and physician specialty $(P=0.57)$. Nurses working outside of pediatric departments $(16.5 \%)$ were more likely than nurses in pediatric departments $(0 \%)$ to correctly identify the age of adolescence as defined by the WHO $(P \leq 0.05)$.

Just over half (53.9\%) of respondents reported having adequate knowledge about the health-care needs of adolescents. Nurses $(69.6 \%)$ reported significantly more agreement with having adequate knowledge of the health-care needs of adolescents as compared with physicians $(45.8 \%)(P \leq 0.001)$. There were no differences in physician and nurse reported knowledge by specialty area or department (physician specialty $P=0.59$; nursing department $P=0.15$ ).

\section{Comfort with clinical management and communication with adolescents}

Of respondents, $58.6 \%$ agreed or strongly agreed that they were comfortable with the clinical management of patients aged 12-18 years. Physicians with specialties other than pediatrics felt somewhat more comfortable with the clinical management of this patient group $(P \leq 0.01)$. There were no differences in the responses found based on profession (physician versus nurse $P=0.15$ ) or nursing department $P=0.90$ ).

Table 2 Health-care providers' self-reported interest, comfort, and knowledge of adolescent health

\begin{tabular}{|c|c|c|c|c|c|}
\hline & $\begin{array}{l}\text { Strongly } \\
\text { disagree or } \\
\text { disagree }\end{array}$ & $\begin{array}{l}\text { Neither } \\
\text { agree nor } \\
\text { disagree }\end{array}$ & $\begin{array}{l}\text { Agree } \\
\text { or strongly } \\
\text { agree }\end{array}$ & $\chi^{2}$ & $P$-value \\
\hline $\begin{array}{l}\text { Adolescents have unique health-care needs that are different } \\
\text { from both children and adults }\end{array}$ & 7.7 & 3.9 & 88.4 & 167.37 & $\leq 0.001$ \\
\hline I have adequate knowledge of the health needs of adolescents & 21.1 & 25 & 53.9 & 44.59 & $\leq 0.00 \mathrm{I}$ \\
\hline $\begin{array}{l}\text { I am comfortable with the clinical management of patients aged } \\
\text { I2-18 years }\end{array}$ & 17.7 & 23.7 & 58.6 & 68.02 & $\leq 0.001$ \\
\hline I am comfortable communicating with patients aged I2-18 years & 9.1 & 18.5 & 72.4 & 162.7 & $\leq 0.00 \mathrm{I}$ \\
\hline I am interested in working with adolescents & 17.2 & 22.8 & 59.9 & 74.85 & $\leq 0.001$ \\
\hline $\begin{array}{l}\text { I am interested in gaining further skills and knowledge in } \\
\text { adolescent health-care }\end{array}$ & 8.2 & 9.5 & 82.3 & 250.66 & $\leq 0.001$ \\
\hline
\end{tabular}


The majority of respondents $(72.4 \%)$ reported that they were comfortable communicating with patients aged $12-18$ years. Nurses $(82.3 \%)$ were more likely to report being comfortable communicating with adolescents than physicians were $(67.3 \%)(P=0.03)$, although physicians in specialty areas other than pediatrics $(77.1 \%)$ reported more comfort communicating with this group when compared with pediatric physicians $(59.7 \%)(P \leq 0.01)$ (Table 2$)$.

\section{Interest in adolescents}

Respondents (59.9\%) agreed or strongly agreed that they were interested in working with adolescents. Interest in working with adolescents was positively associated with the amount of contact that health-care providers had with adolescents $(P \leq 0.01)$.

Respondents reported an interest (82.3\%) in gaining further skills and knowledge in adolescent health-care. This was not dependent upon frequency of contact with adolescents $(P=0.42)$, profession $(P=0.76)$, nursing department $(P=0.94)$, or physician specialty $(P=0.28)$ (Table 2$)$.

\section{Health-care providers' perceptions of the health-care needs of adolescents and their provision of health-care services}

Eighty-four percent of respondents agreed or strongly agreed that adolescents have specific health-care needs that differ from those of both children and adults. This was independent of profession $(P=0.34)$, nursing department $(P=0.22)$, and physician specialty $(P=0.57)$.

Of health-care providers, $26.7 \%$ felt that patients should be transferred from pediatric to adult health-care services at 12-13 years of age. A majority believed that patients should be transferred to the adult health-care setting at an older age, with $21.5 \%$ believing that transfer should occur when the patient is $18-21$ years old. This was independent of profession $(P=0.71)$, physician specialty $(P=0.21)$, and nursing department $(P=0.48)$.

The majority of respondents $(85.8 \%)$ reported that adolescents should be hospitalized in a dedicated adolescent ward. Additionally, $76.7 \%$ of respondents reported that adolescents should have dedicated health-care services.

\section{Discussion}

Adolescents are central to current challenges in global health. ${ }^{14,27}$ Despite over 30 years of calls for action to address adolescent health issues in policy and practice, ${ }^{1,22,28-31}$ however, little change has been made in the health of young people, ${ }^{5,32}$ and adolescent health continues to be an area of neglect. ${ }^{33}$
The majority of health-care providers surveyed in this study reported having regular contact with this patient group. However, respondents also reported a lack of formal education or training in adolescent health. This finding raises questions regarding the ability of the current level of health-care provider education in adolescent health as measured in this study to adequately meet the needs of the health-care system in delivering effective services to this group of patients. A lack of training in adolescent health and/or the health-care issues that are specific to adolescents as compared with adults and children has been identified as an obstacle in achieving adequate health-care for adolescents. ${ }^{34-36}$ In addition, research suggests that specific training in adolescent health can be efficacious in improving clinical skills and practice, ${ }^{35,37-40}$ improving medical trainee confidence ${ }^{40}$ and improving physicians' own perceived competence $e^{35,37}$ in working with young people. Medical and nursing schools in Saudi Arabia need to urgently integrate adolescent health in their curriculums. Continuing professional education training and conferences are important venues to provide practicing health-care providers with the necessary education and training on adolescent health.

The finding that health-care providers lack formal education and training in adolescent health is in line with previous findings ${ }^{41-44}$ Similarly, and in keeping with previous investigations, this study found that the majority of healthcare providers surveyed were interested in working with adolescents and in gaining further skills and knowledge in adolescent health-care. This finding is promising. However, attention to the training needs of health-care professionals for the improvement of adolescent health addresses only one of the many barriers to adolescent health within a health-care setting. For example, Kang et $\mathrm{a}^{45}$ identified structural barriers to service provision for young people, including cost, time, workload, setting, inflexibility, and shortcomings in interservice linkages. Similarly, young people may fail to access health-care services due to shortages in afterhours care, long waiting times, and cost. ${ }^{46}$ Personal concerns on the part of the young person such as feelings of fear, vulnerability, and shame as well as a lack of knowledge regarding the existence of services can also impede the ability of adolescents to access needed services. ${ }^{47}$ Where provider training may help to improve practitioner confidence and competencies in those areas that present the greatest threats to adolescent health and well-being, structural barriers require system change at the policy level. Any attempt to improve adolescent health services should, therefore, identify and target not only professionals but systemic barriers to the effective provision of health-care for young people. 
Although several studies have reported on the barriers to the provision and use of adolescent health services, few attempts have been made to translate this evidence into the design of comprehensive adolescent friendly services. ${ }^{48}$ The health-care providers that participated in this study overwhelmingly agreed that adolescents have needs that differ from both children and adults. In addition, providers believed that adolescents should have dedicated services, and a majority of respondents were not in agreement with the current policy of transferring adolescents from pediatric to adult care at the age of 14 . These findings are in line with international recommendations regarding the provision of youth-friendly services, ${ }^{49-56}$ and represent an opportunity for the improvement of adolescent health-care within the KSA. Future efforts in Saudi Arabia and worldwide should therefore attempt to design and test adolescent-friendly services for their effect on important health-care outcomes.

It is clear that the participants of this study are positive to the advancement of adolescent health-care quality in Saudi Arabia despite their self-reported lack of training in adolescent health. This, however, should be tempered against the fact that this study had a low response rate. We assume, however, that the health-care providers that participated in this study represent that group of providers that are most interested in adolescent health. With this in mind, the training, interest, and perceptions of health-care providers of the health-care needs of young people across NGHA and Saudi Arabia may differ and need to be explored further. As such, there is cause to raise awareness and prioritize adolescent health within Saudi Arabia.

\section{Acknowledgments}

The authors would like to thank Mr Benjamin Marcus for statistical support and Dr Mohamed Qayad for his comments on earlier versions of this work.

\section{Authors' contributions}

FA was responsible for conceiving, designing, and implementing this study. TO was responsible for data analysis and interpretation. FA and TO collaborated on the manuscript preparation and revisions. Both approved the final version of this paper.

\section{Disclosure}

The authors report no conflict of interest to this work.

\section{References}

1. World Health Organization. Adolescent friendly health services: An agenda for change. Geneva, Switzerland, 2002.
2. AlBuhairan F, Areemit R, Harrison A, Kaufman M. Adolescent psychosocial development and evaluation: global perspectives. In: Özdemir Ö, editor. Complementary Pediatrics. 2012. Available from: http://www.intechopen.com/books/ complementary-pediatrics/adolescent-psychosocial-developmentand-evaluation-global-perspectives. Accessed July 5, 2014.

3. Patel V, Fisher AJ, Hetrick S, McGorry P. Mental health of young people: a global public-health challenge. Lancet. 2007;369(9569):1302-1313.

4. Patton GC, Coffey C, Cappa C, et al. Health of the world's adolescents: a synthesis of internationally comparable data. Lancet. 2012;379(9826):1665-1675.

5. Patton GC, Coffey C, Sawyer SM, et al. Global patterns of mortality in young people: a systematic analysis of population health data. Lancet. 2009;374(9693):881-892.

6. Alwan A, MacLean DR, Riley LM, et al. Monitoring and surveillance of chronic non-communicable diseases: progress and capacity in highburden countries. Lancet. 2010;376(9755):1861-1868.

7. Beaglehole R, Bonita R, Horton R, et al. Priority actions for the noncommunicable disease crisis. Lancet. 2011;377(9775):1438-1447.

8. Boutayeb A, Boutayeb S. The burden of non-communicable diseases in developing countries. Int J Equity Health. 2005;4(2):1-10.

9. Dim-Dzietham R, Liu Y, Bielo MV, Shamsa F. High blood pressure trends in children and adolescents in national surveys, 1963 to 2002. Circulation. 2007;116(13):1488-1496.

10. Gore FM, Bloem PJN, Patton GC, et al. Global burden of disease in young people aged 10-24 years: a systematic analysis. Lancet. 2011; 377(9783):2093-2102.

11. Kessler RC, Berglund P, Demler O, Jin R, Merikangas KR, Walters EE. Lifetime prevalence and age-of-onset distributions of DSM-IV disorders in the National Comorbidity Survey Replication. Arch Gen Psychiatry. 2005;62(6):593-602.

12. O'Connell ME, Boat T, Warner KE, editors. Preventing Mental, Emotional, and Behavioral Disorders Among Young People: progress and possibilities. Washington, DC: The National Academies Press; 2009.

13. Catalano RF, Fagan AA, Gavin LE, et al. Worldwide application of prevention science in adolescent health. Lancet. 2012;379(9286): 1653-1664.

14. Sawyer SM, Afifi RA, Bearinger LH, et al. Adolescence: a foundation for future health. Lancet. 2012;379(9826):1630-1640.

15. Viner RM, Ozer EM, Denny S, et al. Adolescence and the social determinants of health. Lancet. 2012;379(9826):1641-1652.

16. Cheng TL, Savageau JA, Sattler Al, DeWitt TG. Confidentiality in health care. A survey of knowledge, perceptions, and attitudes among high school students. JAMA. 1993;269(11):1404-1407.

17. Ford CA, Millstein SG, Halpern-Felsher BL, Irwin CE Jr. Influence of physician confidentiality assurances on adolescents' willingness to disclose information and seek future health care. A randomized control trial. JAMA. 1997;278(12):1029-1034.

18. Wissow L, Fothergill K, Forman J. Confidentiality for mental health concerns in adolescent primary care. Bioethics Forum. 2002;18(3-4): $43-54$.

19. Olson AL, Kelleher KJ, Kemper KJ, Zuckerman BS, Hammond CS, Dietrich AJ. Primary care pediatricians' roles and perceived responsibilities in the identification and management of depression in children and adolescents. Ambul Pediatr. 2001;1(2):91-98.

20. Kramer T, Garralda ME. Psychiatric disorders in adolescents in primary care. Br J Psychiatry. 1998;173:508-513.

21. Little AW, Green A. Successful globalisation, education and sustainable development. Int J Educ Dev. 2009;29(2):166-174.

22. The World Bank. World Development Report 2007. Development and the Next Generation. Washington, DC: The World Bank; 2006. Available from: http://www-wds.worldbank.org/external/default/ WDSContentServer/IW3P/IB/2006/09/13/000112742_2006091311102 4/Rendered/PDF/359990WDR0complete.pdf. Accessed July 5, 2014.

23. Alderman EM, Rieder J, Cohen MI. The history of adolescent medicine. Pediatr Res. 2003;54:137-147. 
24. US Census Bureau [database on the Internet]. International Programs. International Data Base; 2013. Available from: http://www.census. gov/population/international/data/idb/region.php?N=\%20Results $\% 20$ $\& \mathrm{~T}=10 \& \mathrm{~A}=$ separate $\& \mathrm{RT}=0 \& \mathrm{Y}=2014 \& \mathrm{R}=-1 \& \mathrm{C}=\mathrm{SA}$. Accessed April 11, 2014

25. Abdullah MA, Al-Salhi HS, Anani MA, Melendrez LQ. Adolescent endocrinology in Saudi Arabia. Saudi Med J. 2000;21(1):25-30.

26. Saudi Commission for Health Specialties 2011. Available from: http:// www.scfhs.org.sa/en/about/Pages/default.aspx. Accessed 2 August 2014.

27. Williamson N. Motherhood in Childhood: Facing the Challenge of Adolescent Pregnancy. State of the World Population 2013. New York: United Nations Population Fund; 2013. Available from: https://www unfpa.org/webdav/site/global/shared/swp2013/EN-SWOP2013-final pdf. Accessed July 5, 2014.

28. Task Force on Pediatric Education. The future of pediatric education. Evanston, IL; 1978.

29. United Nations. World Youth Report 2003: the Global Situation of Young People. New York: United Nations. Available from: http://www.un.org/ esa/socdev/unyin/documents/worldyouthreport.pdf. Accessed July 5, 2014.

30. World Health Organization. Young people's health: a challenge for society. Report of a WHO Study Group on Young People and Health by the Year 2000. Geneva, Switzerland: World Health Organization; 1986. Available from: http://whqlibdoc.who.int/trs/WHO_TRS_731.pdf. AccessedAugust 10,2014 .

31. World Health Organization. Programming for adolescent health and development, Geneva, Switzerland: World Health Organization; 1999. Available from: http://www.who.int/maternal_child_adolescent/documents/ trs_886/en/. Accessed August 10, 2014.

32. Viner RM, Coffey C, Mathers C, et al. 50-year mortality trends in children and young people: a study of 50-low income, middle-income and high-income countries. Lancet. 2011;377(9772):1162-1174.

33. World Health Organization. Every Woman, Every Child: Strengthening Equity and Dignity Through Health. The Second Report of the independent Expert Review Group (iERG) on Information and Accountability for Women's and Children's Health. Geneva, Switzerland: World Health Organization; 2013. Available from: http://apps.who.int/iris/bitstream/1 0665/85757/1/9789241505949_eng.pdf. Accessed July 5, 2014.

34. Michaud PA, Stronski S, Fonseca H, MacFarlane A; EUTech Working Group. The development and pilot-testing of a training curriculum in adolescent medicine and health. J Adolesc Health. 2004;35(1):51-57.

35. Sanci LA, Coffey CM, Veit DC, et al. Evaluation of the effectiveness of an educational intervention for general practitioners in adolescent health care: randomised controlled trial. BMJ. 2000;320(7229):224-230.

36. Sawyer S, Shea L, Patton G. Do we need specialist units for adolescents hospital? Such units are valuable in Australia. BMJ. 2001; 323(7309):401.

37. Gooding HC, Blood EA, Sharma N. An educational intervention to increase internists' confidence with and provision of preventive services to adolescents and young adults. Teach Learn Med. 2012;24(4):321-326.

38. Lustig JL, Ozer EM, Adams SH, et al. Improving the delivery of adolescent clinical preventive services through skills-based training. Pediatrics. 2001;107(5):1100-1107.

39. Ozer EM, Adams SH, Lustig JL, et al. Increasing the screening and counseling of adolescents for risky health behaviors: a primary care intervention. Pediatrics. 2005;115(4):960-968.

Advances in Medical Education and Practice

\section{Publish your work in this journal}

Advances in Medical Education and Practice is an international, peerreviewed, open access journal that aims to present and publish research on Medical Education covering medical, dental, nursing and allied health care professional education. The journal covers undergraduate education, postgraduate training and continuing medical education
40. Wintersteen MB. Standardized screening for suicidal adolescents primary care. Pediatrics. 2010;125(5):938-944.

41. Sawyer SM, Conn JJ, Reid KJ, et al. Working with young people: evaluation of an education resource for medical trainees. J Paediatr Child Health. 2013;49(11):901-905.

42. Al-Makadma AS, Al-Tannir M. The perceptions of adolescent medicine among health care professionals in Saudi Arabia. J Adolesc Health. 2010;47(6):608-609.

43. Kraus B, Stronski S, Michaud PA. Training needs in adolescent medicine of practicing doctors: a Swiss national survey of six disciplines. Med Educ. 2003;37(8):709-714.

44. McDonagh JE, Minnaar G, Kelly K, O’Connor D, Shaw KL. Unmet education and training needs in adolescent health of health professionals in a UK children's hospital. Acta Paediatr. 2006;95(6):715-719.

45. Kang M, Bernard D, Booth M, et al. Access to primary health care for Australian young people: service provider perspectives. Br J Gen Pract. 2003;53(497):947-952.

46. Jacobson LD, Mellanby AR, Donovan C, Taylor B, Tripp JH. Teenagers' view on general practice consultations and other medical advice. Fam Pract. 2000;17(2):156-158.

47. Bernard D, Quine S, Kang M, et al. Access to primary health care for Australian adolescents: how congruent are the perspectives of health service providers and young people, and does it matters? Aust $N Z \mathrm{~J}$ Public Health. 2004;28(5):487-492.

48. Tylee A, Haller DM, Graham T, Churchill R, Sanci LA. Youth-friendly primary-care services: how are we doing and what need to be done? Lancet. 2007;369(9572):1565-1573.

49. Elster AB, Kuznets NJ. AMA Guidelines for Adolescent Preventive Services (GAPS): recommendations and rationale. Baltimore: Willims \& Wilkins; 1994.

50. Kang M, Bernard D, Usherwood T, et al. Better Practice in Youth Health Final report on research study access to health care among young people in New South Wales: Phase 2, 2005. Available from: http://www.caah.chw edu.au/resources/access_phase_2_report.pdf. Accessed July 5, 2014.

51. Royal College of Pediatrics and Child Health. Bridging the gaps: health care for adolescents, 2003. Available from: http://www.rcpch.ac.uk/system/ files/protected/page/bridging_the_gaps.pdf. Accessed July 5, 2014.

52. Rosen DS, Blum RW, Britto M, Sawyer SM, Siegel DM; Society for Adolescent Medicine. Transition to adult health care for adolescents and young adults with chronic conditions: position paper of the Society for Adolescent Medicine. J Adolesc Health. 2003;33(4):309-311.

53. Society for Adolescent Medicine. Access to health care for adolescents and young adults. J Adolesc Health. 2004;35:342-344.

54. Society for Adolescent Medicine. Health care reform and adolescents an agenda for the lifespan: a position paper of the Society for Adolescent Medicine. J Adolesc Health. 2009;45:310-315.

55. World Health Organization. Global Consultation and Adolescent Friendly Health Services a Consensus Statement. Geneva, Switzerland: World Health Organization; 2001. Available from: http://www.who. int/maternal_child_adolescent/documents/pdfs/who_fch_cah_02.18. pdf. Accessed July 5, 2014.

56. World Health Organization. Adolescent Friendly Health Services: Making it happen. Part I - Formulating national quality standards. Geneva, Switzerland: World Health Organization; Draft Version 2 dated April 12, 2007. Available from: http://www.youthnet.org.hk/adh/4_4Sframework/3 Services_n_commodities/1_Healthsystem/AFHS $\% 20$ making $\% 20 i t \% 20$ happen/Formulate_Stand.pdf. Accessed July 5, 2014.

\section{Dovepress}

including emerging trends and innovative models linking education, research, and health care services. The manuscript management system is completely online and includes a very quick and fair peer-review system. Visit http://www.dovepress.com/testimonials.php to read real quotes from published authors. 